\title{
INTEGRATING ERP AND BPM TO IS CORE IN MBA CURRICULUM: AN INNOVATIVE FRAMEWORK
}

\author{
Ming Wang, California State University, ming.wang@calstatela.edu \\ Xihui Zhang, University of North Alabama,xzhang6@una.edu
}

\begin{abstract}
This paper focuses on integrating Enterprise Resource Planning (ERP) to Business Process Management (BPM) for an Information Systems (IS) Core in the MBA program. From the BPM Common Body of Knowledge, this study identifies four BPM knowledge areas including enterprise system management, business processes management, business performance management, and project management that need to be covered in the MBA curriculum. The appropriate ERP technology components are incorporated into each of the four identified BPM knowledge areas in the proposed innovative framework. This research provides an innovative approach to teach an IS core in the MBA curriculum to meet the global shortage of next generation leaders and professionals in the digital business world.
\end{abstract}

Keywords: Enterprise Resource Planning, ERP, Business Process Management, BPM, IS Core, MBA Curriculum, SAP

\section{INTRODUCTION}

Traditionally, MBA courses often use case analyses to provide MBA students opportunities to apply conceptual materials to industrial practice, but this approach does not need to be applied to an information systems (IS) core in the MBA curriculum. Lacking exposure, visualization, and hands-on practice on actual business information systems, it would be hard for MBA students to learn the knowledge and skills to manage business information systems from the MBA curriculum.

Pedagogical research on teaching an IS course in the MBA curriculum has been conducted from different perspectives in the past decades. Silver et al. (1995) presented a teaching model that has been used in the IS core in the MBA curriculum at several universities. Their model maintained that consequences of information systems in organizations provide a formal foundation for the course to foster a framework for student projects. Desai and Pitre (2009) developed a framework that suggested how the core MBA courses were integrated with specific international factors to create an interactive MBA curriculum through the design of a curriculum based on basic information systems and enterprise resource planning (ERP) concepts. Cullen (2013) developed a new way of thinking about providing IS instruction to MBA students to develop their information skills in terms of case study and framework. Meanwhile, a variety of efforts have been made on teaching the IS core of MBA curriculum from the perspective of information literacy (Cooney, 2005; Fiegen, 2011; O'Connor, 2008). In fact, an issue of the Journal of Business \& Finance Librarianship was devoted to this topic in 2011. In that issue, Fiegen (2011) provided a summary of the past practices. In the same issue, Diekema et al. (2011) offered that "becoming information literate is not a matter of mastering a set of skills, but of learning through practice, and guided by members of a community, to navigate an information environment in increasingly complex ways" (p. 262).

Thus, this paper proposes an innovative framework to integrate ERP to BPM's four major areas: enterprise system management, processes management, business performance management, and project management for the MBA curriculum, which would provide students the opportunity to learn ERP technology with hands-on experience in the enterprise environment. Learning by doing is important in teaching the next generation of digital business leaders. Students need to navigate, explore, and implement ERP systems in order to understand integrated information systems. 


\section{INTEGRATING ERP AND BPM INTO IS CORE IN MBA CURRICULUM}

Organizations are increasingly adopting Business Process Management (BPM) approaches with the growing need for BPM expertise (Bandara et al., 2010). This has resulted in "a strong demand for college graduates prepared with the knowledge of business processes" (Lee, 2008, p. 10). Hadidi (2014) pointed out that development of courses and programs in the BPM area had received huge consideration in academia recently. ERP is an integral part of digital organizations. Research on ERP and BPM education for business curriculum can be traced back to about three decades ago. Porter and McKibbin (1988) emphasized the need to adapt business curriculum to assure that we develop graduates with an integrated understanding of business processes and the ability to work effectively in teams to solve key business problems. Hawking et al. (2004) noted that business had abandoned the vertical, functional organizational structure characteristic of traditional procurement, manufacturing and physical distribution operations in favor of a more horizontal, cross functional structure. They suggested that business school curricula need to mirror this change. The use of ERP as an integrating theme was proposed by Rivetti et al. in 1999.

The use of ERP systems can provide a variety of benefits in the MBA curriculum. Among the most important benefits is the ability of ERP systems to serve as a focal point for integration of knowledge across functional areas. Fedorowicz et al. (2004) indicated that the use of enterprise systems in business curricula is recommended for the purpose of demonstrating both an integrated view of the firm and the use of information technology to support the efficient and effective performance and management of business processes to achieve organizational objectives. Figure 1 illustrates using ERP as an enterprise application interface (EAI) to connect information silos via its interface to provide integrated data and enable existing applications to communicate and share data.

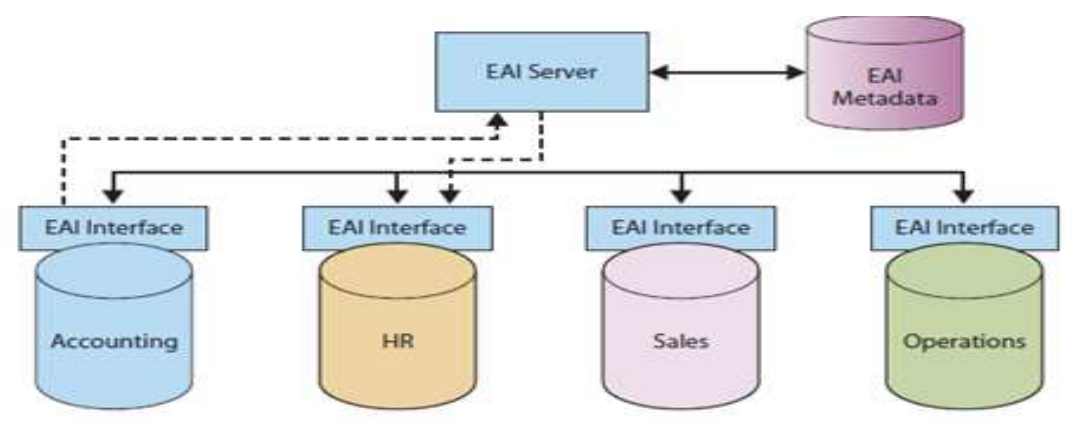

Figure 1. Process and Data integration in ERP

Over the years there has been an increased effort to include more coverage of ERP systems in the business school curriculum (Antonucci et al., 2004). An entire issue on ERP education of the Journal Information Systems Education (JISE) with eight papers, one case study, and one teaching note was published in 2004. Hawking et al. (2004) indicated that in the 1990s there was considerable growth in implementation of ERP Systems. Many universities recognized this demand and the potential of using ERP Systems such as SAP as a teaching tool, and tried to incorporate ERP systems into their curriculum. Chen et al. (2015) empirically examined how ERPsim enhanced student learning outcomes in an IS course. ERPsim is an ERP teaching-learning tool for business students to learn actual SAP and business processes. The study provided empirical evidence that some major IS constructs (e.g., enjoyment and cognitive appraisal of using information systems) play important roles in shaping the effectiveness of using simulation game software to learn business processes and ERP SAP software. Kohers (2015) proposed to integrate ERP into IS cores based on the notable modifications to the Guidelines for Undergraduate Degree Programs in Information Systems (IS) with continuous emphasis towards ERP systems. Iriberri et al. (2015) obtained 230 valid student questionnaires in eight sections of the SAP course for analysis. Their findings indicated that participants had positive perceptions on the usefulness, ease of use, and intention to use the ERP system for the functionality of the system. Singh and Best (2016) also studied interactive visual analysis of anomalous accounts payable transactions in SAP enterprise systems. 


\section{AN INNOVATIVE FRAMEWORK}

Most ERP educators limit the scope of their ERP teaching to technical implementation and configuration issues, rather than addressing more strategic issues tied to BPM knowledge areas. Recognizing this curriculum design limitation, this paper presents an innovative framework to integrate ERP into four BMP core areas. This study identifies four BPM knowledge areas, including enterprise system management, processes management, business performance management, and project management from the BMP Common Body of Knowledge (Benedict et al., 2013) that would need to be covered in the MBA curriculum. Because ERP hands-on activities need to be conducted in the four areas in the framework, SAP is utilized as the ERP software tool in the framework. Introduction of each of the four BPM areas can be followed by a set of SAP hands-on lab modules, teaching cases, and/or simulation games. All the teaching resources can be downloaded from the SAP University Alliances (UA) Curriculum Innovation website.

Table 1. Framework of Transforming ERP in BPM Areas for MBA Curriculum

\begin{tabular}{|c|c|c|}
\hline $\begin{array}{c}\text { BPM Body } \\
\text { Knowledge Areas }\end{array}$ & ERP Knowledge & ERP Skills \\
\hline $\begin{array}{l}\text { Enterprise system } \\
\text { management }\end{array}$ & $\begin{array}{ll}\text { - } & \text { Enterprise architecture } \\
\text { - } & \text { Application platform } \\
\text { - } & \text { Service oriented-architecture (SOA) } \\
\text { - } & \text { Internet security } \\
\text { - } & \text { Information insurance }\end{array}$ & $\begin{array}{ll}\text { - } & \text { To explore SAP NetWeaver } \\
\text { - } & \text { To navigate ERP system } \\
\text { - } \quad \text { To explore SAP Business Suite } \\
\text { - } \quad \text { To identify business procedures, } \\
\text { business applications in SAP }\end{array}$ \\
\hline $\begin{array}{l}\text { Business } \\
\text { processes } \\
\text { management }\end{array}$ & 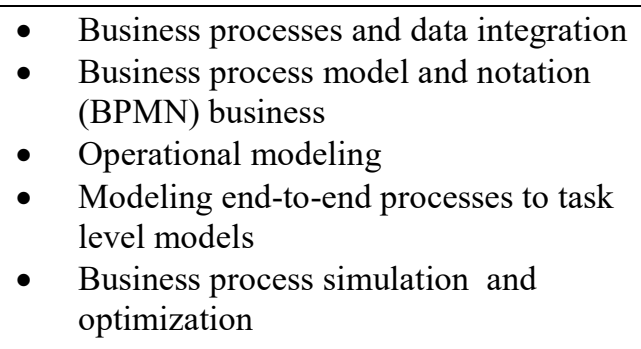 & $\begin{array}{ll}\text { - } & \text { To Implement business process } \\
\text { integration using GBI case study } \\
\text { - } & \text { To perform ERPsim games } \\
\text { - } & \text { Distribution, logistics, } \\
\text { manufacturing and data } \\
\text { analytics }\end{array}$ \\
\hline $\begin{array}{l}\text { Business } \\
\text { performance } \\
\text { management }\end{array}$ & $\begin{array}{ll}\text { - } & \text { BPM maturity assessment using key } \\
& \text { performance indicators (KPI) } \\
\text { - } & \text { Balanced scorecards } \\
\text { - } & \text { Six sigma } \\
\text { - } & \text { Performance dashboards } \\
\text { - } & \text { Business analysis and intelligence }\end{array}$ & $\begin{array}{l}\text { - } \text { Big data in memory } \\
\text { - Us dashboard studio } \\
\text { development } \\
\text { - To create query reporting } \\
\text { - } \quad \text { To conduct descriptive statistics } \\
\text { - } \quad \text { To and predictive statistics } \\
\text { - }\end{array}$ \\
\hline $\begin{array}{l}\text { Project } \\
\text { management }\end{array}$ & $\begin{array}{l}\text { - } \text { Reasons to use ERP project system for } \\
\text { project management } \\
\text { - } \quad \text { ERP project system structure } \\
\text { - } \text { Roles of project system in ERP } \\
\text { Project system data integration and } \\
\text { process automation }\end{array}$ & $\begin{array}{l}\text { - To create the work breakdown } \\
\text { structure (WBS) of a project } \\
\text { - To plan cost and dates using cost } \\
\text { models } \\
\text { - To post actual costs and dates for } \\
\text { WBS elements } \\
\text { - To create reports on project plan } \\
\text { and actual data analysis }\end{array}$ \\
\hline
\end{tabular}

\section{Enterprise System Management}

SAP NetWeaver is the Internet-enabled technical foundation for all SAP applications. SAP NetWeaver provides the development and runtime environment for SAP applications and can be used for custom development and integration with other applications and systems. SAP interface navigation, for example, starts with log-on to SAP, creation of 
multiple sessions, and use of the title bar, menu bar, status bar, command field, functions of different icons and help. Integrating ERP software into the course can help students visualize the organizational structure and enterprise architecture.

Landscaping is the environment where ERP customization activities of configuration are actually performed, tested, and released to production. Configuration activities take place in the development system. The development system includes customizing client, testing client unit, sandbox (prototyping) client, and developing customer processes. SAP recommends that ERP users set up the development system, the quality testing system, and then the production system. Each change made to the system, such as software upgrades and releases, can be tested fully before being released into production. The transport directory is the mechanism to load and test these changes.

\section{Business Processes Management}

A business process is a set of logically related tasks performed to accomplish a business function (McKinney \& Kroenke, 2015). The SAP ERPsim simulation game will provide the ERP environment for students to experience an integrated business process enterprise system. Students can be divided into teams. Each team will operate a logistics company that interacts with its suppliers and customers by sending and receiving orders, delivering its products, and completing the whole logistical cycle.

In the ERPsim Logistics Dairy Game (ERPsim Lab, 2013), participants manage a wholesale distributor of dairy products in the three regions of the German market. Each company buys, distribute, and market dairy products in order to satisfy customer demand and maximize profit. Each team manages an individual dairy distribution company. Each company needs to send products in the regional warehouses in order to sell in the corresponding regions. Teams must decide on and implement product transfer strategies. Success in the game depends on the team's ability to forecast demand in each region for each product and plan procurement and product delivery accordingly. Further, there are costs associated with the delivery of each purchasing order; there are limits in the warehousing capacity, and costs for shipping products to the regional warehouses. Students will get the opportunity to make strategic decisions for product planning, sales forecasts, and fulfillment. It is also designed to highlight the role of data and business intelligence. In order to help students learn the actual use of the SAP system to facilitate business processes in logistics, purchase order process and sales order process are used. Most of the transactions involved in these processes are operational in nature, such as to purchase materials and to deliver products (Léger et al., 2011).

The focus of the ERPsim Logistics Dairy Game is on the full integration of all the business processes. In the Game, participants must manage the procurement process as well as the pricing and material transfers. Figure 2 illustrates four main integrated business processes in the Game: the planning process, the procurement process, the allocation process, and the sales process. The first two business processes are the planning process and the procurement process, managed by the Planning Manager. The responsibility of the Planning Manager is to forecast sales, calculate requirements (run MRP), automatically generate purchase orders, and keep track of the purchase orders.

The next process is the allocation process, managed by the Materials Management Manager. The main responsibility of the Materials Management Manager is to determine a push or pull strategy to make sure the inventory in all of the storage locations is stocked. The Materials Management Manager can also generate an inventory report to see the levels of inventory. The last process is the sales process, managed by the Sales Manager. The Sales Manager is responsible for the pricing of the goods and generating summary and detailed sales reports. 


\section{Issues in Information Systems}

Volume 18, Issue 3, pp. 107-115, 2017

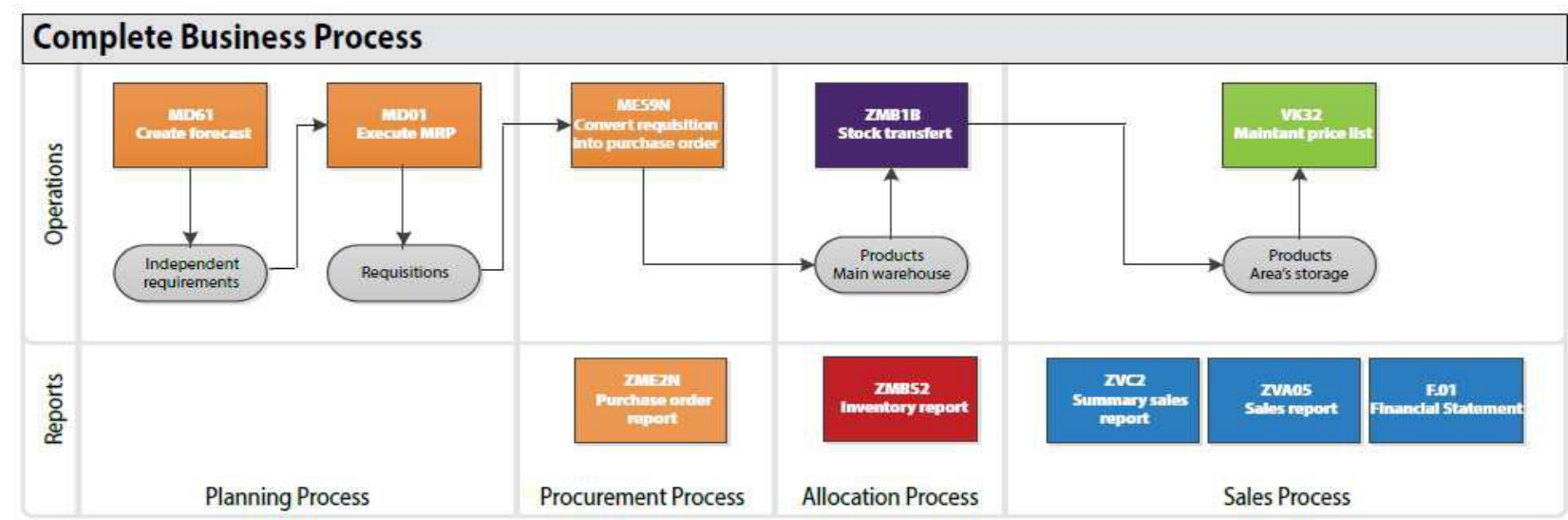

Figure 2. Cash-to-cash Cycle of the Logistics Game

Business process modeling is a set of communication means that can be utilized by the SAP team members in the blueprint phase. Business Process Model and Notation (BPMN) is the standard way of modeling and documenting business processes in most organizations. The other two types of commonly used graphical representations, the deployment flowchart diagram (DFD) and event process chain (EPC) diagram, can also be used for graphical illustration of the business processes. In this proposed course, students will learn how to create BPMN, DFD, and EPC diagrams. Figure 3 illustrates four main integrated business processes in the ERPsim Extended Logistics Game using the BPMN diagram. BPMN is a graphical representation for specifying business processes in a business process modeling. The four roles played by each of the four team members are CEO, Sales Manager, Materials Management Manager, and Planning Manager.

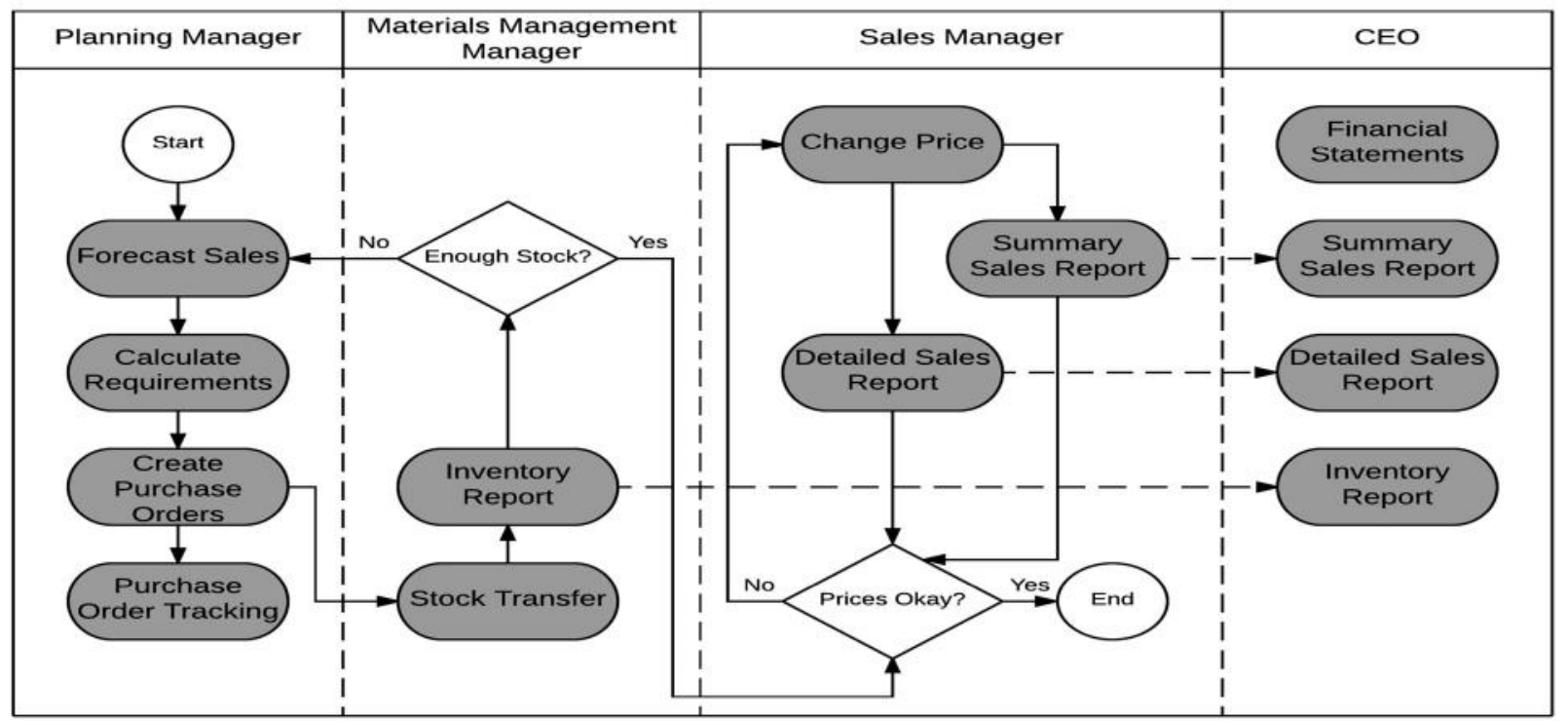

Figure 3. Integrated Business Processes in ERPsim

\section{Business Performance Management}

The enterprise data modeling shows the overall picture of the organizational data employed in different departments, whereas enterprise systems are database applications that provide necessary data for the enterprise business processes. Data in SAP can be classified into four categories: organizational data, master data, situational data, and transaction data. Organizational data are used to represent the structure of an enterprise include client, company, and plant data. Master data represent entities associated with the business processes such as buying materials from vendors and selling 
materials to customers. Situational data are specific to the task being executed, such as who, what, and where. Transaction data are combination of organizational data, master data, and situational data. Transaction data reflect the consequences of process execution. ERP provides two report options: online transaction processing (OLTP) and online analytical processing (OLAP). OLTP generates reports based on transaction data in ERP databases. OLAP generates detailed reports using dedicated analytical tools based on aggregated data in the information structure. Each information structure has characteristics, key figures, and period definition.

More powerful ERP reporting capability is provided in business intelligence. SAP business warehouse (BW) provides users with powerful analytical capabilities known as business intelligence that collect and analyze operational data from a variety of sources for decision making. SAP BW is a separate system that receives data from the SAP system. Unlike the OLAP environment in SAP, SAP BW is not a real time system. Data in SAP BW reports are not tied to SAP real-time transactions and they can be imported from SAP databases, other external databases, or XML data files.

Enterprise data modeling can be top-down or bottom-up. In ERP data modeling, more bottom-up approaches are used for re-engineering and transforming data from existing systems. Business functions with their master data stores can be used for either top-down or bottom-up approaches during the customization of ERP to the organization business processes. Master data stores are used more frequently than the other types of data across ERP systems in both operational systems and analytical systems. Enterprise modeling is to ensure that all applications use these master data stores.

\section{Project Management}

Although Microsoft Project is widely adopted in project management courses for project planning and scheduling, it is relatively difficult to track the actual project cost and manage the complete project life cycle because it is not integrated into ERP systems. Even though Microsoft Project is a piece of project management software, it is not sufficient to calculate the actual project cost in real time due to missing financial accounting, managerial accounting, and human resources data in the enterprise system because it is not integrated in any ERP systems (Franz, 2015). Recognizing the limitations of Microsoft Project as a project management tool, we proposed a comprehensive framework to incorporate ERP SAP Project Systems into the project management course in addition to Microsoft Project.

\section{DISCUSSION}

\section{Summary of Content}

BPM is a discipline involving any combination of modeling, automation, execution, control, measurement, and optimization of business activity flows, in support of enterprise goals, spanning systems, employees, customers, and partners within and beyond the enterprise boundaries (BPM, 2017). ERP is an enterprise platform applied and implemented in most large organizations in the world. In this paper, we proposed an innovative framework which can be used to integrating ERP into four BPM areas, identified through the BPM Common Body of Knowledge, in MBA curriculum. By adopting this framework, fundamental ERP concepts and skills are integrated into BPM areas and introduced in MBA curriculum and significant impacts will be placed on MBA students' career development.

\section{Why SAP}

All the ERP software packages share the similar infrastructure. Any ERP software can be utilized in the proposed framework. Students who have learned SAP will be able to easily learn other ERP software package by themselves (e.g., Johnson et al., 2004). SAP is utilized as the software tool to provide students with hands-on experience in the framework for five reasons: (1) Most Fortune 500 companies use SAP. (2) SAP has the largest market share among all the vendors. As of 2011, SAP had the largest market share based on revenue at $25.5 \%$. This is with a $13.2 \%$ growth from 2010 (Gartner, 2012). (3) Learning SAP will help students with their job placement in large organizations. (4) SAP University Alliances Program provides hosting for SAP software and has developed 
sufficient SAP course materials in different disciplines for faculty and students. (5) SAP provides students exposure to business processes in enterprise systems and helps them understand the infrastructure of integrated business information systems. Figure 4 illustrates the market share of ERP vendors in the world (McKinney \& Kroenke, 2015).

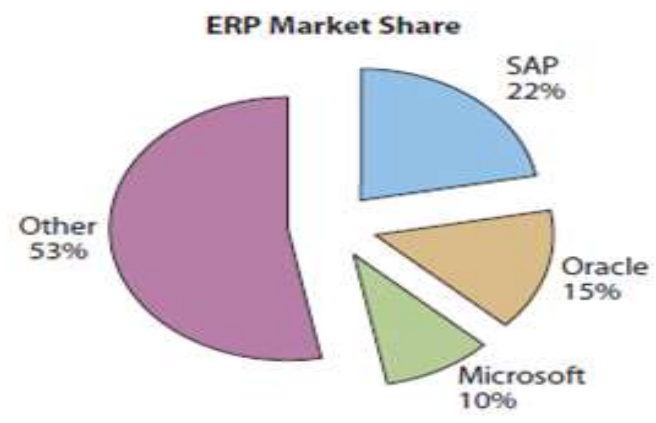

Figure 4. Market Share of ERP Vendors in the World (McKinney \& Kroenke, 2015)

\section{Pedagogical Implications}

The contribution of the paper is to provide educators an innovative framework and approach to integrate ERP into IS core in MBA curriculum. This approach will provide an important and practical guideline for IS curriculum design that is set to follow the shift in IS education from applications development to enterprise software implementation and configuration. The combination of hands-on learning modules and BPM Common Body of Knowledge areas via reading and discussion is an effective approach to teach ERP in MBA programs. The combination of ERP simulation and case teaching can be applied to the business processes management course at the high abstract level.

The hands-on case teaching method is recommended for enterprise systems and application development because they are more technical and need to be taught in the organization context. ERP software is vital to facilitate effective pedagogical methodologies in the proposed framework for ERP education such as hands-on experience, case teaching, technical implementation, and simulation. For illustration purpose, the paper currently is SAP orientated. Institutions can certainly choose other ERP packages such as JD Edwards, Oracle, PeopleSoft, SSA Global, and Microsoft Dynamics. Thus, general usability of the proposed framework is evident.

\section{Limitations and Future Research}

As previously mentioned, this study is built on our extensive curriculum development experiences, market-leading ERP technology skills, and the consistent publication record in pedagogical referred journals in the past decades. The proposed framework, although innovative and practical, is yet to be tested in the extended field. In the future, we plan to collect both quantitative data and qualitative narratives from instructors who have adopted this framework in their teaching and research. With constructive feedbacks, positive experiences, and lessons learned, we hope to be able to improve this framework and make it more effective in integrating ERP into BPM in an IS core in the MBA curriculum.

\section{REFERENCES}

Antonucci, Y., Corbitt, G., Stewart, G., \& Harris, A. (2004). Enterprise systems education: Where are we? Where are we going? Journal of Information Systems Education, 15(3), 227-234.

Bandara, W., Chand, D. R., Chircu, A. M., Hintringer, S., Karagiannis, D., Recker, J., van Rensburg, A., Usoff, C., $\&$ Welke, R. J. (2010). Business process management education in academia: Status, challenges, and recommendations. Communications of the Association for Information Systems, 27(1), 743-776.

Benedict, T., Bilodeau, N., Vitkus, P., Powell, E., Morris, D., Scarsig, M., Lee, D., Field, G., Lohr, T., Saxena, R., Fuller, M., \& Furlan, J. (2013). Guide to the business process management common body of knowledge 
(BPM CBOK version 3.0). Charleston, SC, USA: CreateSpace Publishing.

BPM (2017). https://bpm.com/what-is-bpm

Chen, L., Keys, A., \& Gaber, D. (2015). How does ERPsim influence students' perceived learning outcomes in an information systems course? An empirical study. Journal of Information Systems Education, 26(2), 135146.

Cooney, M. (2005). Business information literacy instruction: A survey and progress report. Journal of Business \& Finance Librarianship, 11(1), 3-25.

Cullen, A. (2013). Using the case method to introduce information skill development in the MBA curriculum. Journal of Business \& Finance Librarianship, 18(3), 208-232.

Desai, M. S., \& Pitre, R. (2009). Developing a curriculum for on-line international business degree: An integrated approach using systems and ERP concepts. Education, 130(2), 184-194.

Diekema, A., Holliday, W., \& Leary, H. (2011). Reframing information literacy: Problem-based learning as informed learning. Library and Information Science Research, 33(4), 261-268.

ERPsim Lab. (2013). ERPsim logistics dairy participant's guide (2012-2013 version). HEC Montreal, Canada, https://erpsim.hec.ca/en/learning. (Note: Login user id and password are needed to access the guide.)

Fedorowicz, J., Gelinas, U. J. Jr., Usoff, C.. \& Hachey, G. (2004). Twelve tips for successfully integrating enterprise systems across the curriculum. Journal of Information Systems Education, 15(3), 235-244.

Fiegen, A. M. (2011). Business information literacy: A synthesis for best practices. Journal of Business \& Finance Librarianship, 16(4), 267-288.

Franz, M. (2015). Project management with SAP project system (4th ed.). Quincy, MA, USA: SAP Press.

Gartner (2012). Market share analysis: ERP software worldwide.

Hadidi, R. (2014). A curriculum to fill the gap between business and technical knowledge to meet the global need for business and industry professionals. International Journal of Education Research, 9(1), 75-87.

Hawking, P., McCarthy, B., \& Stein, A. (2004). Second wave ERP education. Journal of Information Systems Education, 15(3) 327-332.

Iriberri, A., Kwon, O., \& Henson, J. (2015). Integrating an ERP into the curriculum at a business school: The students' perceptions of SAP. Academy of Educational Leadership Journal, 19(2), 99-108.

Johnson, T., Lorents A., Morgan J., \& Ozmun J. (2004). A customized ERP/SAP model for business curriculum integration. Journal of Information Systems Education, 15(3), 245-253.

Kohers, G. (2015). SAP and the introductory management information systems course. Academy of Educational Leadership Journal, 19(1), 65-70.

Lee, J. S. (2008). Status of business process courses in AACSB-accredited undergraduate programs of business. Journal of Computer Information Systems, 49(1), 10-16.

Léger, P. M., Charland, P., Feldstein, H., Robert, J., Babin, G., \& Lyle, D. (2011). Business simulation training in information technology education: Guidelines for new approaches in IT training. Journal of Information Technology Education: Research, 10(1), 39-53. 


\section{Issues in Information Systems}

Volume 18, Issue 3, pp. 107-115, 2017

McKinney, E., \& Kroenke, D. M. (2015). Processes, systems, and information: An introduction to MIS (2nd ed.). Upper Saddle River, NJ, USA: Pearson.

O'Connor, L. G. (2008). The diffusion of information literacy in academic business literature. Journal of Business \& Finance Librarianship, 13(2), 105-125.

Porter, L., \& McKibbin, L. (1988). Management education and development: Drift or thrust into the 21st century? New York, NY, USAP: McGraw-Hill.

Rivetti, D., Schneider, G., \& Bruton, C. (1999). Enterprise resource planning software as an organizing theme for MBA curricula. Academy of Information and Management Sciences Journal, 2(1), 1-7.

Silver, M. S., Markus, M. L., \& Beath, C. M. (1995). The information technology interaction model: A foundation for the MBA core course. MIS Quarterly, 19(3), 361-390.

Singh, K., \& Best, P. (2016). Interactive visual analysis of anomalous accounts payable transactions in SAP enterprise systems. Managerial Auditing Journal, 31(1), 35-63. 